\title{
A administração financeira na pequena empresa: realidade ou ficção?
}

\section{Resumo}

Embora muitas vezes à margem da economia formal, estaria o pequeno empreendedor condenado necessariamente à marginalidade do conhecimento disponível nas escolas de Administração, quer por falta de acesso, quer pelo distanciamento do conhecimento ali apresentado da sua realidade?

Claro está que não podemos anular o valor dos conceitos desenvolvidos na bibliografia amplamente utilizada e recomendada na maioria das IES, ou minimizar os esforços daquelas instituições em apresentar aos seus alunos aquilo que de mais atual ocorre no mundo do conhecimento, ou ainda descartar a iniciativa de autores locais em adaptá-los à realidade doméstica.

No contexto dessas economias, as fontes de recursos financeiros da maioria dos pequenos negócios provêm dos seus próprios iniciadores - ou seja, 100\% capital próprio - todo ele exposto a uma marcante volatilidade do meio-ambiente, sem poder contar com os benefícios do capital de terceiros de longo prazo.

Neste texto, procuramos mostrar que o instrumento de gestão financeira que pode ajudar o empreendedor na sua saga do dia-a-dia é a administração de Capital de Giro, apresentando mais especificamente uma aplicação do chamado fluxo de caixa, instrumento de fácil compreensão e pronta aplicação à realidade do pequeno negócio, podendo se constituir no embrião de um sistema de informações gerenciais (SIG) mais abrangente.

\section{Abstract}

Although most of the small businesses in the so- called underdeveloped economies operate on the fringe of legacy, does it mean they will be necessarily excluded from the use of basic concepts of sound management practices that are taught at most Business Schools or are present in large organizations?

This question has called the attention of a number of authors - particularly on issues concerning the financial management of small enterprises - where the capital issue is of prime interest in such economic environments that show chronical lack of savings,or don't have active capital markets that would provide the small entrepreneur with long range funds.

This article intends to present the idea that although people operating small outfits don't enjoy an easy life,they can use the financial management concepts on their day-to-day, beginning with the Cash Flow Projections as the starting point for an improved decision making process and as the first step for building a more compreehensive Management Information System(MIS) that will enhance the chances of its survival and potential growth.

\section{A importância da administração financeira na pequena empresa}

Peter Drucker ${ }^{1}$ informa que " a maioria dos executivos ...aprendeu que não existe uma fórmula mágica para a medição do desempenho de uma empresa..., uma empresa precisa de um certo número de 'mostradores' para ter controle."

Para tanto, apresenta 5 medidores: cinco dessas 'escalas' poderão mostrar como a empresa está indo e se está se movendo na direção certa. São elas:

1. A posição da empresa nos mercados onde atua.

2. As realizações da empresa como inovadora bem sucedida em seus mercados.

*Mestre em em Administração Contábil-Financeira, FGV. Especialista em Administração de Empresas. Engenheiro Mecânico. Coordenador do Curso de Administração das Faculdades Integradas "Campos Salles".

'DRUCKER,Peter F. Administrando para o Futuro. São Paulo: Pioneira,1992. p. 173 -176 
3. A produtividade da empresa que relaciona os fatores de produção ao 'valor adicionado' que eles produzem.

4. Liquidez e fluxos de caixa.

5. Lucratividade.

Como vemos, dos cinco indicadores, três são de natureza econômico-financeira. No contexto da realidade brasileira, a administração financeira adquire uma dimensão ampliada como decorrência da falta crônica de capitais - característica das economias em desenvolvimento.

Sabemos que nenhuma medida tomada isoladamente é a melhor. Sabemos, também, que a maioria dos textos em administração - principalmente aqueles produzidos nos países centrais - 'fala' para a grande organização - quer se trate de uma empresa, um hospital ou uma universidade - com ou sem objetivos de lucros.

Especificamente neste trabalho, voltaremos nossa atenção para a administração de Capital de Giro na pequena e média empresa, para concluir sugerindo que o 'Fluxo de Caixa Projetado' ou o 'Orçamento de Caixa' possibilita ao empreendedor um maior conhecimento do funcionamento do seu negócio, simulando e manipulando as informações de forma simples a fim de aumentar suas possibilidades de sucesso.

Isto, porque se sabe de há muito que uma empresa pode operar sem lucros por muito tempo, desde que tenha um fluxo de caixa adequado. A falta de liquidez - 'a falta de caixa' causa muito mais dano do que um aperto na lucratividade.

E' o próprio Peter Drucker quem afirma : "A liquidez é fácil de medir e altamente previsível. Uma simples projeção do fluxo de caixa é,normalmente, suficiente para a identificação dos fluxos de caixa e das necessidades de caixa"2.

Além disso - dadas as limitações que cercam o empreendedor e seu pequeno negócio, a simplicidade de elaboração de um fluxo de caixa projetado torna-o um instrumento mais acessível ao seu entendimento, constituindo-se em um primeiro passo para a construção de um sistema de informações gerenciais mais abrangente e completo.

\section{Uma visão geral da administração de capital de giro}

Esta parte do trabalho apresenta uma visão geral da administração do capital de giro, analisando alguns conceitos e definições fundamentais, bem como a sua abrangência, objetivos e responsabilidades.

\subsection{Algumas Definições}

As primeiras definições baseiam-se no Balanço Patrimonial (BP) da empresa, como aparece na figura 2.1. As contas do BP podem ser agrupadas em cinco categorias:
$\mathrm{AC}=$ ativos circulantes
$\mathrm{AP}=$ ativos permanentes
$\mathrm{PC}=$ passivos circulantes
ELP $=$ exigível a longo prazo e
$\mathrm{PL}=$ patrimônio líquido

A conhecida equação do BP mostra que o total dos ativos é igual ao total das fontes de recursos, ou seja, $\mathrm{AC}+\mathrm{AP}=\mathrm{PC}+\mathrm{ELP}+\mathrm{PL}$.

O capital de giro (CAPITAL DE GIRO) é definido muitas vezes como os ativos circulantes especificamente caixa e títulos negociáveis, contas a receber e estoques. Em um sentido mais amplo - e talvez mais útil - podemos nos referir a capital de giro como o conjunto dos ativos circulan-

\section{Figura 2.1. - Modelo de Balanço Patrimonial}

\begin{tabular}{|c|c|}
\hline ATIVOS & PASSIVOS \\
\hline $\begin{array}{l}\text { Caixa \& Bancos } \\
\text { Títulos Negociáveis } \\
\text { Contas A/R } \\
\text { Estoques }\end{array}$ & $\begin{array}{l}\text { Contas A/P } \\
\text { Salários \& Ordenados A/P } \\
\text { Impostos A/P } \\
\text { Empréstimos de C.P. } \\
\text { Outras Contas A/P }\end{array}$ \\
\hline Ativos Circulantes(AC) & Passivo Circulante(PC) \\
\hline $\begin{array}{l}\text { Equipamentos } \\
\text { \& Instalações } \\
\text { Marcas \& Patentes } \\
\text { Intangíveis } \\
\text { Ativo Permanente(AP) }\end{array}$ & $\begin{array}{l}\text { Exigível de LP (ELP) } \\
\text { Capital Social } \\
\text { Lucros Retidos } \\
\text { Patrimônio Líquido(PL) }\end{array}$ \\
\hline
\end{tabular}

${ }^{2}$ Idem-p. 175 


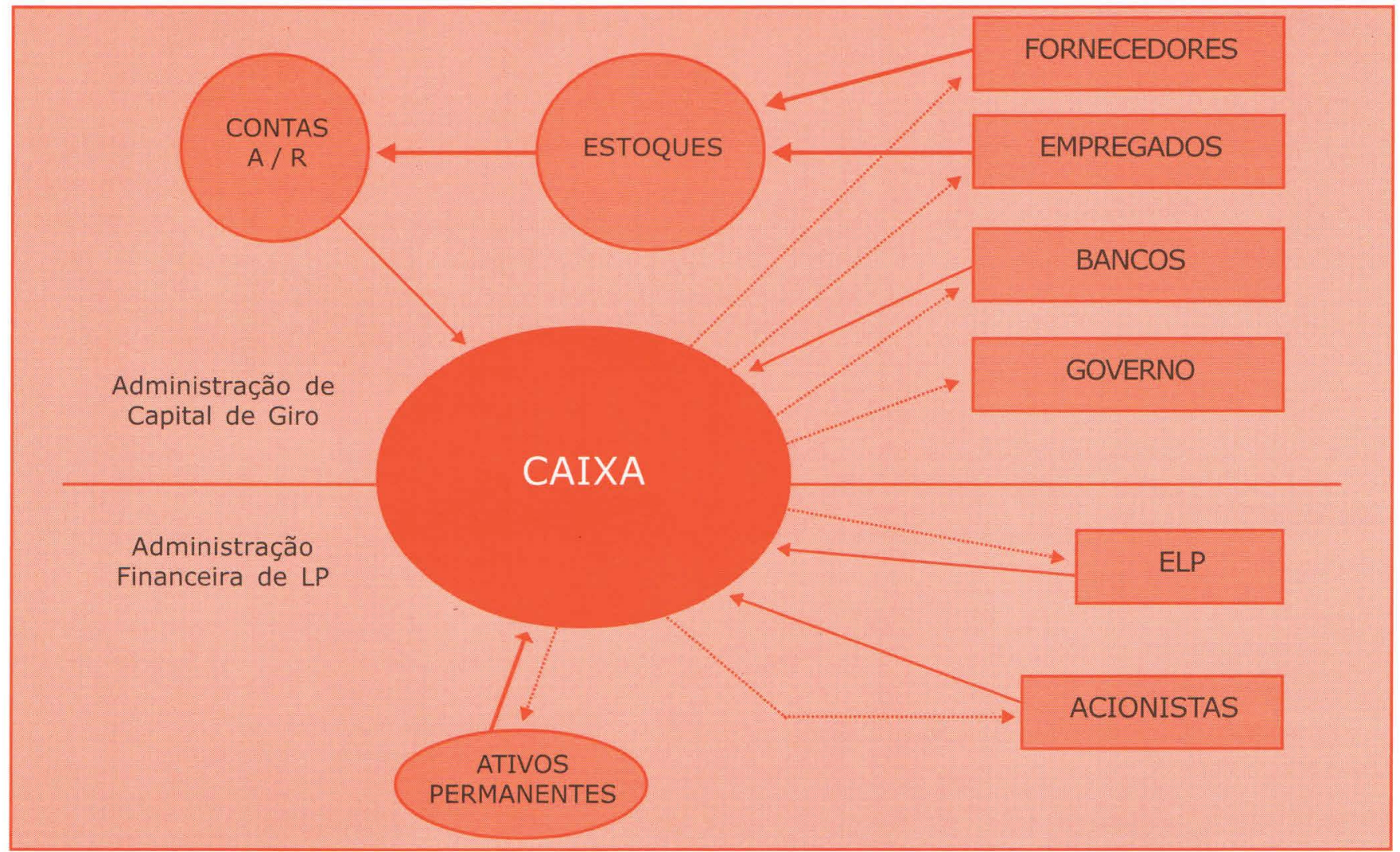

tes e os passivos circulantes - que incluem contas a pagar, empréstimos de curto prazo e demais contas e obrigações a pagar em menos de um ano. Entende-se por capital de giro líquido - também chamado de capital circulante líquido (CCL) - a diferença entre os ativos circulantes e os passivos circulantes, AC - PC , constituindo-se em uma única entidade monetária. A administração do capital de giro corresponde ao conjunto de práticas para gerir ativos circulantes, passivos circulantes e suas inter-relações.

A figura 2.2. mostra o fluxo monetário na empresa e proporciona uma visão mais ampla da administração de capital de giro.

Observe-se que é semelhante ao BP da figura 2.1. em vários aspectos. Em primeiro lugar, observe-se que as setas escuras representam o fornecimento de ativos não monetários. Os fornecedores suprem recursos materiais de todos os tipos usados na produção ou na prestação de serviços e os funcionários fornecem mão-de-obra (trabalho). As demais setas na Figura 2.2. representam o fluxo monetário de entrada e saída das várias fontes de financiamento anteriores com as outras contas. As setas contínuas indicam entrada de caixa e as setas pontilhadas indicam saída de caixa.

Em segundo lugar, devemos notar a importância de empregados e governo como fontes específicas de financiamento. Em terceiro lugar, podemos dividir a Figura 2.2. em uma parte superior e outra inferior. A parte inferior corresponde à administração financeira de longo prazo(LP) representando as decisões financeiras de LP que devem ser tomadas pela empresa. Do lado do ativo, as decisões correspondem aos ativos permanentes, enquanto que do lado direito as decisões se referem à estrutura de capital da empresa incluindo a política de dividendos.

Em contrapartida, a parte superior da Figura 2.2. corresponde à administração do capital de giro, representando as interligações entre ativos circulantes (AC) e passivos circulantes (PC). O círculo maior - na figura - salienta a importância do caixa, embora o nível de recursos em caixa costuma ser o menor entre todos os ativos da empresa. $\mathrm{O}$ caixa é representado tanto como parte da admi-

${ }^{3}$ Adaptado de Keith V.Smith - Management of Working Capital - St.Paul, USA: West Publishing, 1975 . p. 6 
nistração de capital de giro como parte da administração financeira de LP, na medida em que os recursos devem estar disponíveis para o pagamento de todos os fornecedores e das fontes de financiamento. O fluxo contínuo de recursos do caixa para fornecedores, de fornecedores para os estoques, dos estoques para contas a receber e daí de volta para o caixa, é muitas vezes denominado ciclo de caixa ou ciclo operacional da empresa. Este é o principal conjunto de relações que constituem o cerne da administração de capital de giro(CG). Mas, ao mesmo tempo, a administração de CAPITAL DE GIRO abrange mais do que simplesmente as contas específicas de ativos e passivos circulantes.

Assim - ainda com base na Figura 2.2. - é útil conceituar fluxo de caixa como diretamente relacionado com CAPITAL DE GIRO. Uma definição específica de fluxo de caixa seria entradas menos saídas de caixa. Em um sentido mais amplo - mais útil - entendemos por fluxo de caixa o conjunto de todas as entradas e saídas de caixa da empresa juntamente com as inter-relações apresentadas na Figura 2.2.

\section{Pequena empresa: componente vital da economia}

É fácil notar a importância dos grandes negócios, dada a sua grande presença tanto no cotidiano das pessoas como pela visibilidade marcante nos meios de comunicação. As pequenas empresas simplesmente desaparecem no meio dos grandes nomes: Petrobrás, Shell, Volkswagen, Banć do Brasil, Nestlé, Cia.Vale do Rio Doce, entre outras, constantemente monitoradas pela imprensa, pelo rádio e pela TV.

Embora as pequenas empresas chamem menos atenção, suas contribuições específicas ao bem es$\operatorname{tar}$ da sociedade colöcam-nas como um componente vital da Economia.

O jornalista Alberto Tamer nos informa: "Uma das conclusões é que a pequena e média empresa está sustentando o crescimento econômico norte-americano e que elas apresentam um enorme potencial de criação de emprego, principalmente na Europa, pois esse tipo de atividade rompe a rigidez da legislação trabalhista e abre espaço para um novo mercado de mãode-obra ainda não aproveitado"4 .

\subsection{O que é pequena empresa?}

Qualquer critério para definir pequenas empresas é necessariamente arbitrário, na medida em que padrões diferentes são adotados para objetivos diferentes, o que torna mais distante a adoção de um critério único e dificulta a medição da participação e importância do setor.

Uma determinada legislação pode excluir pequenas empresas de certas regras e incluí-las em outras. Assim, uma empresa pode ser considerada isenta para efeito de IR, mas que não seja considerada microempresa na legislação estadual ou municipal, porque estaria sujeita ao pagamento de ISS ou de ICMS.

Além disso, uma empresa pode ser considerada 'pequena', quando comparada a outras maiores, mas ser considerada 'grande', quando comparada a empresas menores. Postos de gasolina, padarias, casas lotéricas de proprietários individuais seriam - em geral - classificadas como pequenas empresas. Da mesma forma, haveria consenso em classificar como grande empresa uma montadora de veículos. As empresas entre esses tamanhos seriam classificadas como grandes ou pequenas, dependendo do ponto de vista de cada analista. Podemos utilizar vários critérios para conceituar pequenas empresas, como, por exemplo, o número de empregados, o volume de vendas ou o valor dos ativos ou outros critérios qualitativos. Na prática, prevalecem os critérios quantitativos.

Para referência do nosso trabalho, adotaremos o critério do Sebrae que classifica as empresas pelo número de funcionários.

\subsection{A importância da pequena empresa como produtora de Bens \& Serviços.}

As empresas pequenas operam em todos os setores, mas diferem significativamente em sua natureza e importância de um setor para o outro.

Conforme o SEBRAE, as pequenas e médias

${ }^{4} \mathrm{~A}$. Tamer - São as pequenas empresas que criam empregos nos EUA - O Estado de São Paulo, 11 de julho de 1999. 
Quadro 3.1. Demonstrativo dos critérios oficiais de classificação das Empresas ${ }^{5}$

\begin{tabular}{|c|c|c|}
\hline Entidade & Critério & \\
\hline \multirow{5}{*}{$\begin{array}{l}\text { SEBRAE - Serviço Brasileiro de Apoio } \\
\text { às Micro e Pequenas Empresas }\end{array}$} & \multirow{2}{*}{\multicolumn{2}{|c|}{ Número de pessoas ocupadas }} \\
\hline & & \\
\hline & $\begin{array}{l}\text { Micro - } \\
\text { Pequena - } \\
\text { Média - } \\
\text { Grande - }\end{array}$ & $\begin{array}{l}\text { Até } 19 \text { pessoas } \\
\text { de } 20 \text { a } 99 \\
\text { de } 100 \text { a } 499 \\
\text { acima de } 500\end{array}$ \\
\hline & \multicolumn{2}{|l|}{ b) Comércio } \\
\hline & $\begin{array}{l}\text { Micro - } \\
\text { Pequena - } \\
\text { Média - } \\
\text { Grande - }\end{array}$ & $\begin{array}{l}\text { Até } 9 \text { pessoas } \\
\text { de } 10 \text { a } 49 \\
\text { de } 50 \text { a } 99 \\
\text { acima de } 100\end{array}$ \\
\hline
\end{tabular}

Quadro 3.2. Distribuição das empresas por porte e setor - Brasil $(\%)^{6}$

\begin{tabular}{|l|c|c|c|c|c|c|}
\hline Setor & Composição & ME & PE & MDE & GE & Total \\
\hline Indústria & 15,02 & 81,35 & 13,65 & 4,41 & 0,59 & 100,00 \\
\hline Comércio & 52,45 & 91,28 & 7,88 & 0,56 & 0,28 & 100,00 \\
\hline Serviços & 32,53 & 93,64 & 5,43 & 0,48 & 0,44 & 100,00 \\
\hline Total & 100,00 & 90,66 & 7,89 & 1,08 & 0,38 & 100,00 \\
\hline
\end{tabular}

\begin{tabular}{|l|c|c|c|c|c|c|}
\hline \multicolumn{7}{|c|}{ Quadro 3.3. Distribuição do pessoal segundo porte e setor - Brasil $(\%)^{7}$} \\
\hline Setor & Composição & ME & PE & MDE & GE & Total \\
\hline Indústria & 43,99 & 17,90 & 23,70 & 36,61 & 21,79 & 100,00 \\
\hline Comércio & 33,00 & 51,13 & 29,14 & 7,76 & 11,97 & 100,00 \\
\hline Serviços & 23,01 & 45,48 & 18,11 & 6,00 & 30,41 & 100,00 \\
\hline Total & 100,00 & 35,23 & 24,23 & 20,08 & 20,46 & 100,00 \\
\hline
\end{tabular}

empresas representam um universo de aproximadamente 4,5 milhões de estabelecimentos industriais, comerciais e de serviços, distribuídos conforme quadro abaixo:

Entretanto, o fato de inúmeras empresas pequenas aparecerem em cada setor não nos diz muito sobre sua relativa importância. As pequenas empresas poderiam ser uma minúscula parte em alguns setores ou poderiam ser tão numerosas e produtivas que seu resultado agregado superasse o das grandes empresas. Qual o resultado total de bens e serviços na Economia proporcionado pela empresa de pequeno porte?

Uma forma simples é comparar o número de em- pregados ocupados nas pequenas empresas com o número de empregados nas grandes empresas, como mostra o quadro a seguir:

Como podemos observar, a participação das micro e pequenas empresas no total de empregos no Brasil é da ordem de 59,5\%.

Os setores diferem dessa média geral. No comércio, onde os pequenos negócios predominam, 80\% de todos os empregados trabalham em empresas com menos de 100 pessoas. Supondo que todos os trabalhadores sejam igualmente produtivos, podemos concluir que $80 \%$ do resultado desse setor provém de empresas de pequeno porte.

${ }^{5}$ Fonte: SEBRAE-Serviço Brasileiro de Apoio às Micro e Pequenas Empresas - Micro e Pequena Empresa no Brasil - Dados Selecionados . Brasília, 1996

${ }^{6}$ Sebrae-Micro e Pequena Empresa no Brasil-Dados Selecionados . Brasília, 1996.

${ }^{7}$ Idem 
Nos serviços, elas respondem por praticamente $64 \%$ do resultado, enquanto que na indústria sua contribuição cai para aproximadamente $42 \%$. As estimativas do Sebrae ${ }^{8}$ indicam que elas são responsáveis por $48 \%$ do total da produção nacional, $42 \%$ dos salários pagos e cerca de $30 \%$ do PIB e, como vimos, $59 \%$ dos postos de trabalho.

\subsection{Contribuições Especiais da Pequena} Empresa

Observa-se um rápido aumento na participação do total de empregos em pequenos empreendimentos no Brasil. As razões desse crescimento não parecem claras, mas podemos especular sobre alguns dos seus fatores determinantes:

a) novas tecnologias permitem uma produção eficiente em escalas menores, possibilitando o trabalho em casa, como, por exemplo, o desenvolvimento de softwares pelo uso de redes de computadores;

b) aumento no desemprego gerado por programas de melhorias nas grandes organizações permitem a ex-empregados iniciarem seus próprios negócios (franquias);

c) terceirização da mão de obra pela qual exempregados passam a prestar serviços aos seus expatrões;

d) flexibilidade no horário de trabalho que permite o ingresso de um maior contingente de mão de obra feminina no mercado de trabalho em casa, venda de porta em porta etc.

Embora a contribuição econômica geral dos pequenos empreendimentos já seja significativa, ela apresenta um potencial de crescimento. Entretanto, as pequenas empresas apresentam algumas qualidades que de certa maneira as tornam miniaturas das grandes organizações. Segundo Longenecker ${ }^{9}$, elas podem oferecer as seguintes contribuições especiais:

\subsubsection{Novos Empregos}

Como vimos, enquanto as grandes empresas estão 'enxugando' seus quadros e demitindo funcionários, as pequenas empresas, em contrapartida, vêm criando novos postos de trabalho.

\subsubsection{Introdução de Inovações}

É interessante notar que muitos avanços tecnológicos se originaram de inventores independentes e pequenas organizações, enquanto que os departamentos de $P \& D$ das grandes empresas tendem a aperfeiçoar produtos já existentes. Uma extensa relação de produtos - que vão desde o zíper até os computadores digitais passando pelas canetas esferográficas e a fibra ótica - confirma a contribuição de inventores independentes e das pequenas organizações ${ }^{10}$

\subsubsection{Estímulo à Concorrência}

A concorrência atua como regulador que transforma o egoísmo em atendimento. Em uma situação competitiva, os indivíduos são conduzidos pelo interesse próprio a agirem de uma maneira socialmente desejável. Em princípio, a presença de muitas empresas pequenas saudáveis em um setor econômico é condição necessária - embora não suficiente - para que a concorrência se desenvolva.

\subsubsection{Auxílio a grande empresa}

As pequenas empresas podem desempenhar algumas funções com mais eficiência do que uma grande empresa. Destacam-se entre elas a distribuição e o fornecimento.

Distribuição : É difícil imaginar-se a comercialização - tanto no atacado como no varejo - de um grande número de produtos de consumo, sem a presença de pequenos estabelecimentos comerciais na prestação de um valioso serviço unindo produtores e clientes. Os números do SEBRAE mostram isso.

Fornecimento : As pequenas empresas atuam como subcontrantes e fornecedores especializados.

${ }^{8}$ Ibidem

${ }^{9}$ LONGENECKER, Justin G. et al. Administração de Pequenas Empresas. São Paulo: Makron Books, 1997.p.34

${ }^{10}$ STONER, James A.F; FREEMAN R.E. Administração.Rio de Janeiro: LTC: 1999. p. 117 
Atuam também na prestação de serviços aos clientes de grandes empresas, como, por exemplo, na assistência técnica.

\subsubsection{Produção eficiente de bens $\&$ serviços.}

O tamanho eficiente de um negócio varia de setor para setor. Um grande empreendimento parece operar melhor na produção de veículos, dada a economia de escala necessária, enquanto que pequenas empresas se destacam em consertá-los. A presença permanente de pequenas empresas em um sistema econômico parece indicar sua eficiência evidenciando seu papel fundamental como agente impulsionador do sistema capitalista, criando novos produtos, novos mercados e sobrepondo-se aos antigos métodos menos eficientes e mais caros.

\subsection{Aspectos distintivos do Gerenciamento da Pequena Empresa}

Qualquer crescimento de riquezas está limitado à capacidade gerencial do empreendedor. Esta parece ser uma premissa do capitalismo que passa despercebida por muitos. Quando não obedecida, pode responder pelas situações inesperadas de falências, concordatas, quebras etc..

Sabemos que essa perspectiva ou "fantasma" paira sobre todas as empresas - independentemente de seu porte - principalmente aquelas chamadas de pequenas ou médias.

Como apresentado no Quadro 3.4, os 'fatores econômicos' são a principal causa dos fracassos nos

\begin{tabular}{|l|c|}
\hline \multicolumn{2}{|c|}{$\begin{array}{c}\text { Quadro 3.4. - Dun \& Bradstreet } \\
\text { Business Failure Record }-1992^{11}\end{array}$} \\
\hline Causas & Percentagem de fracassos \\
\hline Negligência & 3,1 \\
\hline Acidente & 1,6 \\
\hline Fraude & 1,4 \\
\hline Fatores Econômicos & 45,0 \\
\hline Relativas à Experiência & 10,5 \\
\hline Financeiras & 37,2 \\
\hline Estratégicas & 1,2 \\
\hline
\end{tabular}

negócios (45\% do total). Incluem-se nesta categoria fatores como 'vendas inadequadas', 'lucros insuficientes' e 'fracas perspectivas de crescimento'. A segunda categoria importante são as 'causas financeiras' que incluem componentes como 'elevadas despesas operacionais' e 'capital insuficiente'.

Aparece em $3^{\circ}$ lugar a intrigante causa 'relativa à experiência' - com 10,5\% do total. Essas causas se relacionam com a qualidade de gestão que inclui 'falta de conhecimento sobre negócios', 'falta de experiência no ramo' e a 'falta de experiência gerencial', o que equivale a dizer que o fracasso resulta de gerenciamento de baixa qualidade. Assim, se entendermos que 'vendas inadequadas', 'lucros insuficientes' e 'elevadas despesas operacionais' podem servir como eufemismos para o gerenciamento inadequado, podemos concluir que a qualidade de gerenciamento é uma causa importante no fracasso das pequenas empresas.

Ainda que grandes empresas possam ter um gerenciamento deficiente, a ineficiência gerencial parece ser a fraqueza característica da empresa pequena. Embora saibamos que a gerência - tanto das grandes como das pequenas empresas desempenhe funções similares, os problemas de gestão de uma pequena empresa seriam diferentes daqueles enfrentados pelas grandes?

O empreendedor ocupa-se com atividades rotineiras no seu dia-a-dia, ficando desse modo impedido de ter uma visão mais abrangente do seu negócio.

Um dos maiores problemas de gestão do empreendedor é a inabilidade em estabelecer as prioridades dos problemas empresariais e na coordenação do planejamento e execução de ações conjuntas. Falta-lhe uma visão abrangente que possibilite a integração dos aspectos tecnológicos, administrativos, financeiros, humanos e ambientais que caracterizariam um plano de negócios.

Tais fraquezas são típicas das pequenas empresas. Entretanto, o gerenciamento deficiente não é inevitável - mesmo porque, dada a relativa simplicidade do seu funcionamento - não há necessidade de um conhecimento de técnicas administrativas tão sofisticadas. Nesse sentido, é importante

${ }^{11}$ LONGENECKER, Justin G. et al. Administração de Pequenas Empresas. São Paulo: Makron Books, 1997.p. 42 
a elaboração de um Plano formal de negócios que não se limita a negócios que estão recém começando - mas valem para todos os empreendimentos - nos seus diferentes estágios de desenvolvimento - colocando o planejamento como um processo contínuo na gestão de todo empreendimento.

\section{A administração de Capital de Giro na pequena empresa}

Nada mais importante no ponto de vista financeiro para a pequena empresa do que a administração do CAPITAL DE GIRO, e nada mais frustrante para o pequeno empreendedor envolvido no seu dia-a-dia com a administração de caixa, contas a receber, estoques e contas a pagar - muitas vezes sem ter a quem recorrer. Entretanto, sabemos que a administração dos ativos circulantes e passivos circulantes é de grande importância para a maioria dos pequenos empreendedores. Sabemos - também - quantas excelentes oportunidades de negócios foram desperdiçadas pela má administração dos ativos e passivos circulantes da empresa.

\subsection{O Ciclo de CAPITALDEGIRO}

Como apresentado na Figura 2.2. do item1, é fundamental que o pequeno empresário compreenda o ciclo de CAPITAL DE GIRO - tanto em termos dos prazos envolvidos, como em termos da quantidade de investimento exigida em estoques e contas a receber. $\mathrm{O}$ não entendimento dessas relações fundamentais é causa de profundos problemas financeiros para as pequenas empresas.

O ciclo de CAPITAL DE GIRO da empresa representa o fluxo de recursos através das contas circulantes como parte das operações do dia-a-dia. Assim, por exemplo, as empresas compram ou produzem estoques. Vendem esses estoques à vista ou a crédito. Recebem as contas resultantes das vendas a crédito e, a seguir, reiniciam esse processo como ilustrado na Figura 2.2.

Podemos visualizar a seqüência cronológica de um ciclo de CAPITAL DE GIRO apresentando os eventos, à medida que eles acontecem, iniciando com os investimentos em estoques e terminando com a cobrança de contas a receber. As datas do exemplo são as seguintes, como ilustrado na Figura 4.1. :

Dia 15 de agosto - Encomenda de estoque para atender vendas futuras;

Dia 31 de agosto - Recebimento do estoque encomendado;

Dia 30 de setembro - Pagamento dos produtos recebidos em estoque;

Dia 15 de outubro - Revenda do estoque a crédito;

Dia 30 de novembro - Recebimento dos clientes da venda realizada.

As conseqüências do investimento e financiamento do ciclo de CAPITAL DE GIRO - como

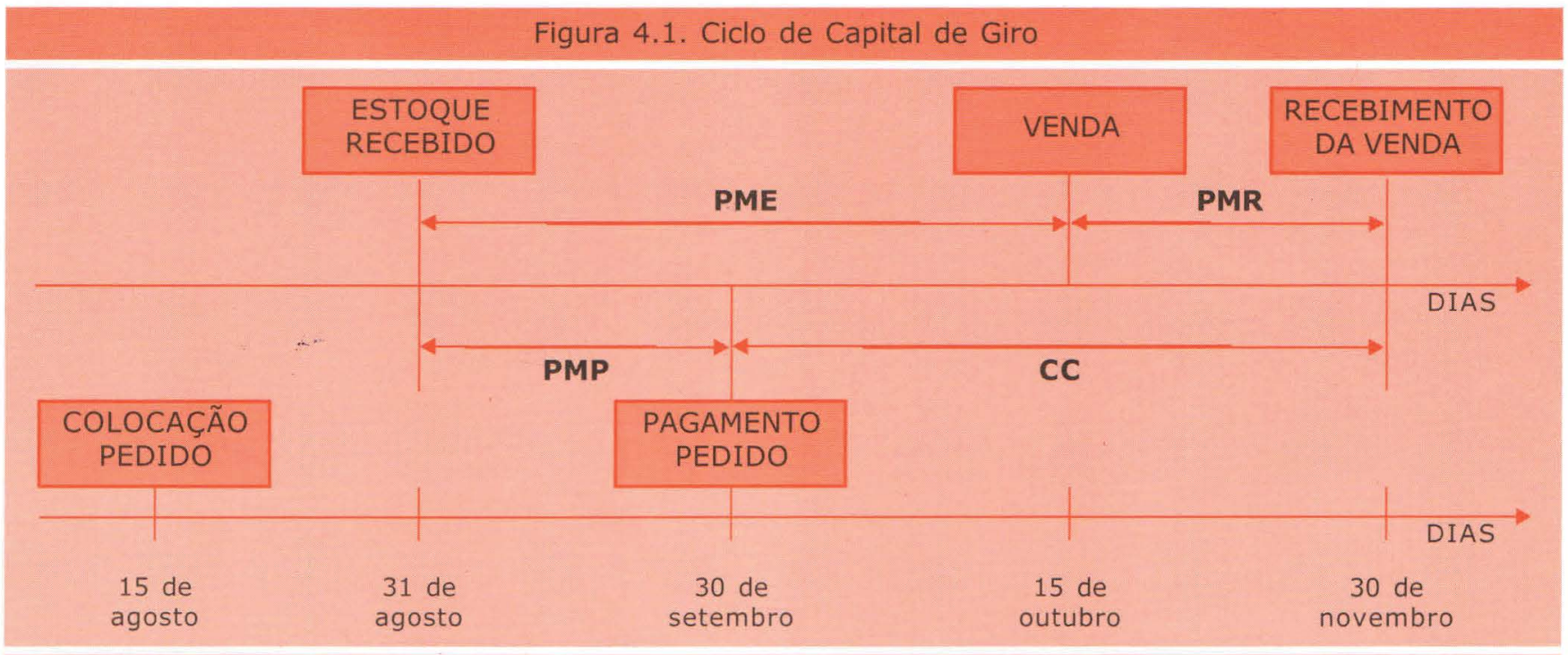

$C C=P M E+P M R-P M P=45+46-30=61$ 
ilustrado na Figura 4.1., são:

1. Dia 15 de agosto, a empresa coloca seu pedido junto ao fornecedor;

2. A empresa investe em estoque do dia 31 de agosto (data do recebimento do pedido) até o dia 15 de outubro, quando é realizada a venda. Este período é denominado Período Médio de Estoque (PME) - que, no exemplo, corresponde a 45 dias;

3. O fornecedor concede um prazo de pagamento, para os itens em estoque, de 31 de agosto até o dia 30 de setembro. Este período é denominado Período Médio de Pagamento(PMP) - que, no exemplo, corresponde a 30 dias;

4. A empresa concede um prazo de pagamento aos seus clientes que vai do dia 15 de outubro (data da venda) até a data do efetivo recebimento (30 de Novembro). Este período é denominado de Período Médio de Recebimento (PMR) - que, no caso, corresponde a 46 dias;

5. Desse modo, a empresa deverá financiar seu investimento desde o dia 30 de setembro - data do pagamento ao fornecedor - até o dia 30 de novembro - data do recebimento da venda - que eqüivale, no nosso caso, a 60 dias.Esse período de tempo é denominado de Ciclo de Caixa - $\mathrm{CC}=$ $\mathrm{PME}+\mathrm{PMR}-\mathrm{PMP}=45+46-30=61$ dias. Ele representa o número de dias necessários, para que a empresa possa completar o ciclo de CAPITAL DE GIRO,que termina com a conversão das contas a receber em caixa.Durante esse período, a empresa não conta com o financiamento (contas a pagar) oferecido pelo fornecedor. Quanto maior o CC da empresa, maior será o potencial de problemas no fluxo de caixa da empresa e vice-versa. Esta situação favorável de CAPITAL DE GIRO é ilustrada na Figura 4.2., na qual, no momento em que a empresa tem de pagar suas compras (30 de novembro), ela já vendeu seu estoque (15 de outubro) e recebeu dos seus clientes (30 de novembro). Assim seu Ciclo de Caixa é de praticamente zero, uma vez que o fornecedor está financiando suas necessidades de CAPITAL DE GIRO.

Os exemplos apresentados anteriormente resumem - de maneira bastante clara - as estratégias básicas que devem ser utilizadas pela pequena empresa na administração de seu CAPITAL DE GIRO:

1. Ampliar - tanto quanto possível - o período médio de pagamentos (PMP), ou seja, obter o maior prazo de pagamento possível de seus fornecedores.

2. Girar os estoques com a maior rapidez possível, a fim de reduzir o período médio de estoques (PME), ou seja, trabalhar com os menores níveis de estoque possível - evitando faltas que possam causar interrupção na produção e ou perda de vendas.

3. Receber o mais cedo possível suas contas a receber, a fim de reduzir ao máximo o Período Médio de Recebimento.

A conjunção das três estratégias acima promoverá uma redução no Ciclo de Caixa - como demonstrado nas Figuras 4.1. e 4.2 - financiando seu

Figura 4.2. Ciclo de Capital de Giro

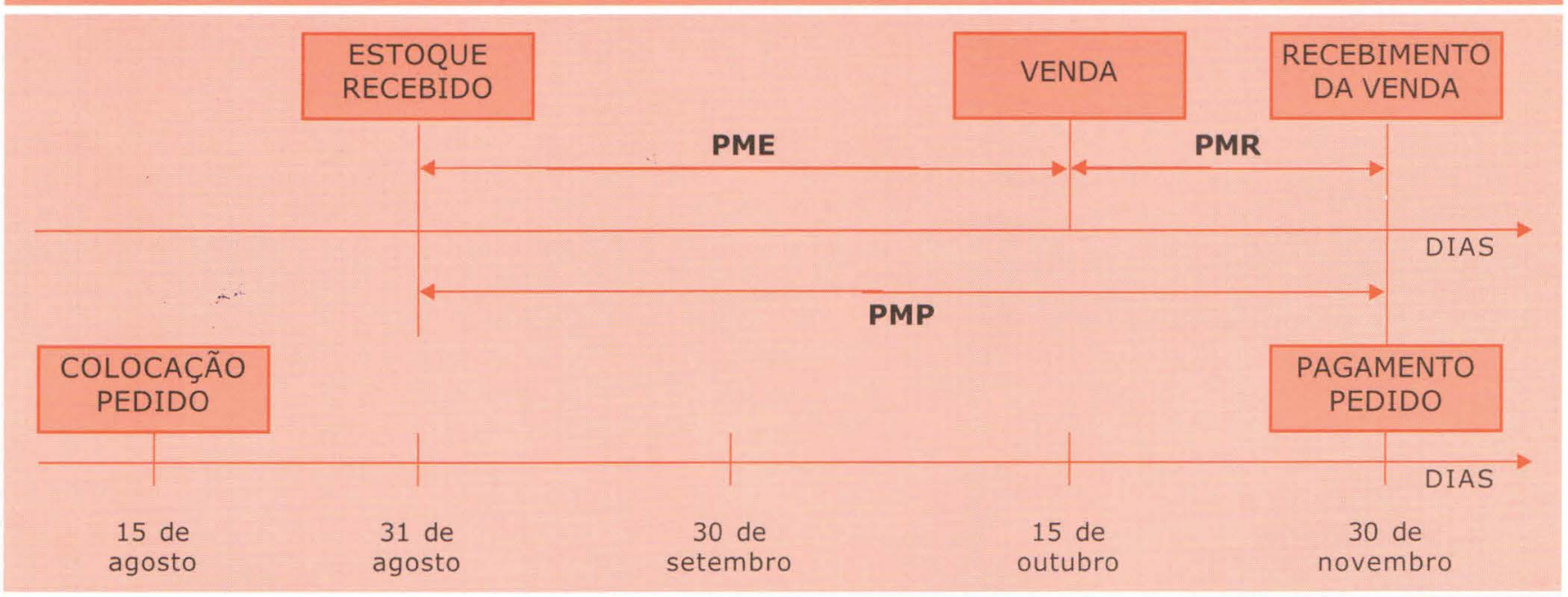

$C C=P M E+P M R-P M P=45+46-90=01$ 
investimento em contas a receber e estoques e prevenindo problemas de fluxo de caixa. Trata-se, na verdade, da essência da gestão de CAPITAL DE GIRO que deveria ser motivo de atenção do gestor de uma pequena empresa.

\subsection{A administração do fluxo de caixa $-\mathrm{O}$} orçamento de caixa.

A natureza tipicamente variável dos fluxos de entrada e saída de caixa torna necessário que eles sejam compreendidos e controlados. Há entradas de caixa, quando os clientes pagam pelos produtos ou serviços e, há saídas de caixa, quando os pagamentos são feitos aos fornecedores - por exemplo.

O orçamento de caixa é uma ferramenta para a administração do fluxo de caixa. Difere das demais demonstrações financeiras, na medida em que se preocupa exclusivamente com as entradas e saídas de dinheiro.Utilizando o orçamento de caixa,o empresário poderá prever e planejar o fluxo de caixa de sua empresa.

"Orçamento de caixa, ou projeção de caixa, é um demonstrativo dos fluxos das entradas e saídas projetadas de caixa da empresa, usado para estimar suas necessidades de caixa a CP. A empresa dedica particular atenção ao planejamento de excedentes e faltas de cai$x a$, pois poderá planejar investimentos a $\mathrm{CP}$, se esperar sobras de recursos, ao passo que poderá se preparar com antecedência para obter financiamento em caso de falta de caixa." 12

Tipicamente, o orçamento de caixa é elaborado por um período de um ano - dividido em intervalos mensais e apresenta o formato do Quadro 4.3.

Os componentes do formato geral do orçamento de caixa são descritos de maneira ampla como segue:

- os recebimentos incluem todos os itens que determinam as entrâdas de caixa em qualquer período. Seus componentes normalmente correspondem às vendas à vista, cobrança de vendas a prazo e outros recebimentos - resultantes de outras fontes que não as vendas;

- os pagamentos correspondem a todos os desembolsos de caixa nos períodos. Incluem o paga-

\begin{tabular}{|c|c|c|c|}
\hline \multicolumn{4}{|c|}{$\begin{array}{c}\text { Quadro 4.3.- Formato Geral do } \\
\text { Orçamento de Caixa }\end{array}$} \\
\hline Fluxo & janeiro & fevereiro... & dezembro \\
\hline Recebimentos & & & \\
\hline (-) Pagamentos & & & \\
\hline $\begin{array}{l}\text { (=) Saldo de caixa } \\
\text { operacional }\end{array}$ & & & \\
\hline $\begin{array}{l}\text { (+) Saldo inicial } \\
\text { de caixa }\end{array}$ & & & \\
\hline $\begin{array}{l}(=) \text { Saldo de caixa } \\
\text { antes de financiamento }\end{array}$ & & & \\
\hline (+/-)Financiamento/Aplicações & & & \\
\hline Saldo final & & & \\
\hline
\end{tabular}

mento de fornecedores, aluguéis, ordenados e salários, impostos, pagamento de juros, entre outros;

- o saldo de caixa operacional é determinado, subtraindo-se o total de pagamentos dos recebimentos de cada período;

Somando-se o saldo inicial de caixa ao saldo de caixa operacional, chega-se ao saldo de caixa final de cada período;

- se o saldo final de caixa for negativo, um financiamento será necessário. Caso o saldo final de caixa seja positivo, haverá um saldo excedente que poderá ser aplicado.

Podemos ilustrar o processo de preparação de um orçamento de caixa através de um exemplo de aplicação.

\section{Orçamento de caixa - um exemplo de aplicação}

Vamos examinar o caso da Mirim, para a qual procuraremos aplicar as recomendações de um modelo que, como vimos, podemos denominar de Fluxo de Caixa Projetado.

\subsection{Recebimentos}

Os recebimentos incluem todos os itens, a partir dos quais temos as entradas de caixa a cada mês. São exemplos típicos de recebimentos as vendas à vista, a cobrança de vendas a crédito e recebimentos eventuais (outros recebimentos).

A projeção de vendas da Mirim previstas para o período de janeiro a junho do ano 2002 estão apre-

${ }^{12}$ L.J.Gitman - Princípios de Administração Financeira . 7 ed. São Paulo : Harbra, 1997.p. 590 
Tabela 5.1.- Projeção de Vendas

\begin{tabular}{|l|c|}
\hline Mês & Valor em \$ milhares \\
\hline janeiro & 270 \\
\hline fevereiro & 160 \\
\hline março & 140 \\
\hline abril & 280 \\
\hline maio & 160 \\
\hline junho & 250 \\
\hline
\end{tabular}

Tabela 5.3.- Projeção de Vendas

\begin{tabular}{|l|c|}
\hline Mês & Valor em \$ milhares \\
\hline janeiro & 140 \\
\hline fevereiro & 100 \\
\hline março & 80 \\
\hline abril & 90 \\
\hline maio & 100 \\
\hline junho & 50 \\
\hline
\end{tabular}

Tabela 5.2. Programação de Recebimentos da Mirim

\begin{tabular}{|lcccccc|c|}
\hline & & janeiro & fevereiro & março & abril & maio junho \\
\hline Previsão de Vendas (Faturamento) & & 270 & 160 & 140 & 280 & 160 & 250 \\
\hline Vendas à Vista & $20 \%$ & 54 & 32 & 28 & 56 & 32 & 50 \\
\hline Cobranças & & & & & & & \\
\hline $\mathbf{3 0}$ dias & $40 \%$ & & 108 & 64 & 56 & 112 & 64 \\
\hline $\mathbf{6 0}$ dias & $40 \%$ & & & 108 & 64 & 56 & 112 \\
\hline Total de Rendimentos (A) & & 54 & 140 & 200 & 176 & 200 & 226 \\
\hline
\end{tabular}

Tabela 5.4. Programação de Pagamentos

\begin{tabular}{|c|c|c|c|c|c|c|c|}
\hline & & janeiro & fevereiro & março & abril & maio & junho \\
\hline Compras Previstas & & 140 & 100 & 80 & 90 & 100 & 50 \\
\hline Compras à Vista & $10 \%$ & 14 & 10 & 8 & 9 & 10 & 5 \\
\hline 30 dias & $50 \%$ & & 70 & 50 & 40 & 45 & 50 \\
\hline 60 dias & $40 \%$ & & & 56 & 40 & 32 & 36 \\
\hline Salários \& Ordenados & & 32 & 32 & 32 & 32 & 32 & 32 \\
\hline Aluguéis & & 20 & 20 & 20 & 20 & 20 & 20 \\
\hline Juros & & & & 10 & & & 10 \\
\hline Amortização Empréstimos & & & & & & & 30 \\
\hline Impostos & $20 \%$ & 54 & 32 & 28 & 56 & 32 & 50 \\
\hline Novo Equipamento & & & 10 & & & & \\
\hline Pró-Labore & & 4 & 4 & 4 & 4 & 4 & 4 \\
\hline Total de Rendimentos (A) & & 124 & 178 & 208 & 201 & 175 & 237 \\
\hline
\end{tabular}

Tabela 5.5. Orçamento de Caixa

\begin{tabular}{|c|c|c|c|c|c|c|}
\hline & janeiro & fevereiro & março & abril & maio & junho \\
\hline Total de Recebimentos (A) & 54 & 140 & 200 & 176 & 200 & 226 \\
\hline Total de Recebimentos (A) & 124 & 178 & 208 & 201 & 175 & 237 \\
\hline Fluxo Operacional de Caixa $(\mathrm{C})=(\mathrm{A})-(\mathrm{B})$ & -70 & -38 & -8 & -25 & 25 & -11 \\
\hline Saldo Inicial de Caixa (D) & 100 & $\rightarrow 30$ & -8 & -16 & -41 & -16 \\
\hline
\end{tabular}


sentadas na Tabela 5.1.

Sabendo que a empresa vende $20 \%$ do total de suas vendas à vista, cobra $40 \%$ das vendas em 30 dias e os restantes $40 \%$ em 60 dias, podemos montar o quadro de recebimentos como apresentado na Tabela 5.2.

\subsection{Pagamentos}

Os pagamentos incluem todo os desembolsos de caixa nos períodos sob consideração. Entre os itens mais comuns, estão:

Compras à vista;

Pagamentos de duplicatas;

Aluguéis;

Ordenados e Salários;

Pagamento de impostos;

Juros sobre empréstimos;

Amortização de Empréstimos;

Retiradas de sócios (pró-labore).

A Mirim prevê compras de fornecedores, como apresentado na tabela 5.3.

A empresa planeja pagar à vista $10 \%$ de suas compras, $50 \%$ em 30 dias e o restante $40 \%$ em 60 dias. Sabe-se, ainda, que a folha de pagamentos (salários e ordenados) totaliza 32 mil; aluguéis de 20 mil precisam ser pagos mensalmente; o pagamento de juros de 10 mil vencem em março e o restante em junho; em junho, a empresa amortizará 30 mil de um empréstimo; os impostos correspondem a $20 \%$ do faturamento; a empresa pretende adquirir em fevereiro um novo equipamento no valor de $10 \mathrm{mil}$. A retirada dos sócios corresponde a 4 mil por mês. Com base nesses dados podemos montar a programação de pagamentos como apresentada na Tabela 5.4.

\subsection{Orçamento de Caixa}

Sabendo-se que a empresa dispunha de um saldo de caixa de 100 mil no início de janeiro, podemos determinar os saldos finais de caixa de cada mês, compondo-se o Orçamento de Caixa com os valores das últimas linhas das Tabelas 5.2 e 5.4., como apresentado na Tabela 5.5.

\subsection{Conclusões}

A tabela 5.5. apresenta o orçamento de caixa - consolidando o total de recebimentos e desembolsos - calculando-se o Saldo de Caixa Operacional e o Saldo Final de Caixa antes de qualquer Financiamento - de acordo com o formato geral apresentado no item 4.

O caixa inicial de janeiro de 2002 corresponderia à soma dos valores de Caixa e Bancos apresentado no Balanço encerrado em 2001.

Finalmente, o Gráfico 6.1. apresenta os saldos de caixa antes do financiamento, onde se observa que a empresa apresenta problemas de fluxo de caixa durante praticamente os 6 primeiros meses do ano.

Alguém poderia argumentar que:

"Muito bem, mas os proprietários - em função de sua vivência - já sabiam que teriam problemas de caixa ao longo do primeiro semestre do ano!".

Verdade! Mas é aqui que reside uma das vantagens do fluxo de caixa projetado - como instrumento de administração do CAPITAL DE GIRO: ele permite, de maneira preventiva, determinar em que períodos os problemas deverão - ou terão maior probabilidade - de ocorrer e, mais ainda, determinar os montantes envolvidos.

Desse modo, sabemos dizer que o período mais crítico para a administração do fluxo de caixa são os meses de abril e junho, bem como dimensionar o tamanho do problema: em abril, haverá o maior déficit de caixa da ordem de $\mathrm{R} \$ 41$ mil e, nos demais meses até junho, esse déficit será da ordem de R $\$ 30$ mil - passando por um mínimo de 8 mil em fevereiro e um máximo de 27 mil em junho como apresentado no Gráfico 6.1.

Esta constatação permitirá aos proprietários da empresa identificarem possíveis cursos de ação para resolverem seus problemas de caixa, com antecedência suficiente para selecionarem e negociarem a melhor alternativa.

Assim, com base no fluxo de caixa projetado dentro das hipóteses formuladas - eles agora sabem que terão necessidade de um máximo de R\$ 41 mil para fechar o ciclo de CAPITAL DE GIRO da empresa - passando por um mínimo de 8 mil.

É exatamente neste aspecto que reside a enorme vantagem do fluxo de caixa projetado - não apenas como instrumento de administração do CAPITAL DE GIRO - mas pela visão interativa que proporciona do impacto das diferentes decisões que os administradores podem tomar sobre o 
resultado da empresa - antes de tomá-las. Grife-se o 'antes de tomá-las'!

Assim, poderíamos testar uma decisão de ordem mercadológica:

"E se, em uma dada situação competitiva tivermos de reduzir nossos preços e conseqüentemente o faturamento?"

"Qual a maior redução de faturamento que a empresa poderia suportar - antes de comprometer a sua sobrevivência?"

"Qual o impacto de diferentes flutuações no volume de vendas sobre as necessidades de CAPITAL DE GIRO? O que aconteceria com o fluxo de caixa?"

Observa-se que inúmeras hipóteses podem ser testadas ou - combinações de diferentes cenários comprovando sua enorme capacidade como instrumento de análise de sensibilidade e tomada de decisão.

Assim - apenas a título de exemplo - poderíamos usar nosso modelo para avaliar o resultado de diferentes variações no volume de vendas. O Gráfico 6.2. apresenta o resultado para um aumento de $5 \%$ nas vendas - onde constatamos que a empresa permanecerá até o mês de abril com problemas de caixa necessitando de um financiamento
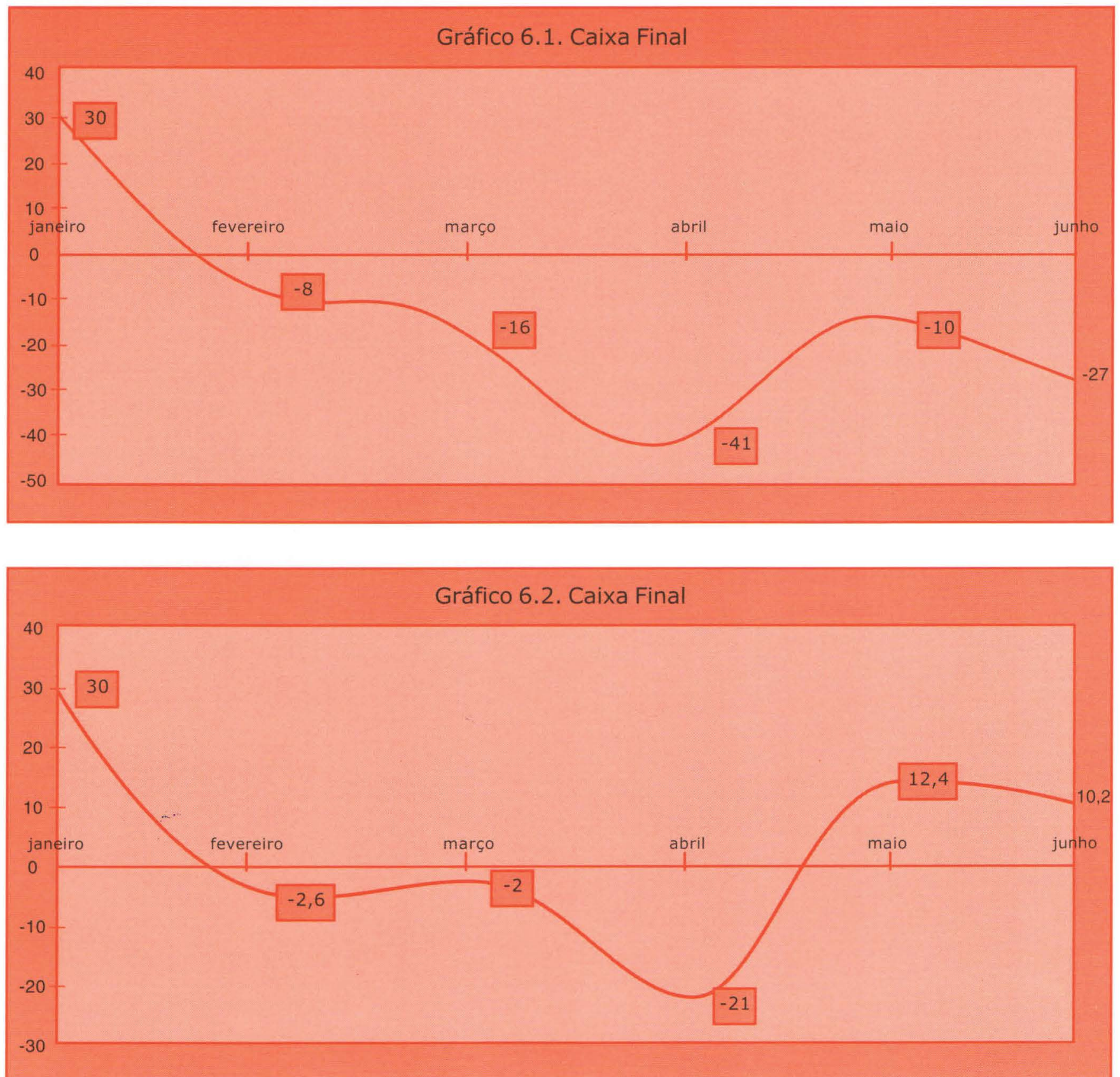
máximo da ordem de $\mathrm{R} \$ 21$ mil.

Teria a empresa condições de conseguir linhas de crédito - nesse montante - junto a seus fornecedores, bancos e demais credores? Caso não conseguisse, qual o maior financiamento disponível? Estariam seus proprietários em condições de suprir a diferença, pela injeção de recursos próprios, via um aumento de capital? Os proprietários estariam dispostos a investir esta quantia adicional? $\mathrm{Ou}$ considerariam descontinuar a atividade, caso não ocorresse um aumento de vendas?

Comprova-se, assim, que o fluxo de caixa projetado pode ser utilizado como um poderoso instrumento - não apenas de administração de CAPITAL DE GIRO - mas de administração estratégica - que permite ao proprietário da pequena empresa testar diferentes decisões e avaliar seu impacto nos resultados do seu empreendimento.

\section{REFERÊNCIAS BIBLIOGRÁFICAS}

DRUCKER, Peter F. Administrando para o futuro . São Paulo: Pioneira,1992.

GITMAN, L. J. Princípios de Administração Financeira. 7.ed. São Paulo: Harbra, 1997.

GROPELLI, A. A , Administração Financeira . 3.ed. São Paulo: Saraiva, 1998.

HOJI, Masakazu. Administração Financeira : uma abordagem prática. São Paulo: Atlas,1999.

LONGENECKER, J. G.; MOORE,C.W. e PETTY,J.W. Administração de pequenas empresas. São Paulo : Makron Books, 1997.

MEGGINSON, L. C. Administração: conceitos e aplicações . 4. ed. São Paulo: Harbra, 1998.

MONTANA, P. J. Administração. São Paulo: Saraiva, 1998.

OLIVEIRA, D. P. R. de. Estratégia empresarial : uma abordagem empreendedora. 2.ed. São Paulo: Atlas, 1991. Planejamento estratégico: conceitos, metodologia \& práticas. 12.ed. São Paulo: Atlas, 1998.

ROSS, Stephen et al. Administração Financeira. São Paulo:Atlas,1995.

SEBRAE - Serviço Brasileiro de Apoio às Micro e Pequenas Empresas. Micro e Pequena Empresa no Brasil - Dados Selecionados. Brasília, 1996.

SEBRAE -SP - Documentação para abertura de empresa . São Paulo, 1998.

SEBRAE - SP - Como abrir sua empresa. Manual Prático. São Paulo, 1997.

SEBRAE-SP - Micro e pequena no Brasil - Dados Selecionados. Brasília, 1996.

SMITH, Keith V. - Management of working capital . St.Paul, USA: West Publishing Co.,1975.

STONER, James A.F; FREEMAN, R.E. Administração. Rio de Janeiro: LTC, 1999.

TAMER, A. São as pequenas empresas que criam empregos nos EUA. O Estado de São Paulo, São Paulo, 11 de jul.1999. 